\title{
EDITORIAL
}

\section{Medical Professionalism: during COVID-19 Times and Beyond}

\author{
Subhash C Parija ${ }^{1}$, Balachandra V Adkoli
}

\begin{abstract}
This article is third in the series of articles exploring the role of professionalism in medical education. In the earlier episodes, we have discussed, the meaning and importance of medical professionalism, and the challenges involved in teaching this key component in the undergraduate medical curriculum based on competency-based medical education (CBME). However, the pandemic of COVID-19 has shocked the entire medical education system. Nevertheless, it has forced the medical colleges to explore alternate modes of online teaching. With this development, the role of various stakeholders, the faculty, the students, medical colleges, regulators, and the civil society will drastically change as the technology will take the central stage. We offer some concrete suggestions, which include reorganization of faculty, upgrading of IT infrastructure and simulation labs, retraining of the faculty and students in tune with the technology, and synergizing faculty development with internal quality assurance. We conclude that development of medical professionalism is a long-drawn agenda and we need to collect further evidence, which will take time.
\end{abstract} Keywords: Competency-based medical education, Faculty development program, Medical education, Portfolio, Professionalism, Quality assurance.

SBV Journal of Basic, Clinical and Applied Health Science (2020): 10.5005/jp-journals-10082-02265

\section{INTRODUCTION}

Professionalism lies at the heart of every profession. Medical professionalism has been discussed and debated widely for its impact on the society. Because, a medical professional deals with the life and death situation. In our series of articles dedicated to this issue, we defined the contours of a medical professionalism in line with diverse roles played by the medical faculty. ${ }^{1}$ In the second part, we focused on the teaching-learning and curriculum matters, which are most vulnerable in developing professionalism.

The competency-based medical education (CBME) launched by the Medical Council of India ( $\mathrm{MCl}$ ) has indeed started with a conceptual model involving features, such as clear delineation of competencies at all levels, a well-designed foundation course, early clinical exposure, introduction of Attitude, Ethics and Communication (AETCOM) modules, emphasis on integration, impetus to skill acquisition through simulation labs, and revised assessment strategy. ${ }^{2}$ Emphasis has been laid on feedback, formative assessment, and continuous internal assessment combined with a log book or portfolio approach. Since the CBME has been a "de novo" experiment in Indian medical education, one is not sure if this model really works. Nevertheless, the medical colleges are working on its refinement, especially in view of the flexibility given to them in many aspects of curriculum.

While these developments have been taking place, the biggest blow has come in the form of COVID-19 pandemic which has shattered the whole world in all walks of life. The medical colleges which were never prepared to handle this kind of a situation have been struggling to cope up with the situation by introducing various modalities of online teaching and learning. ${ }^{3}$ We will examine the implications of these issues from the point of view of professionalism. We attempt to flag a few suggestions to move forward, lest we are trapped by the "stalemate" kind of a situation.

The basic tenets of professionalism will remain the same irrespective of whether it is COVID time or not. On the contrary, they get amplified and find a new meaning in the context of COVID
${ }^{1}$ Sri Balaji Vidyapeeth (Deemed to be University), Puducherry, India

${ }^{2}$ Centre for Health Professions Education, Sri Balaji Vidyapeeth (Deemed to be University), Puducherry, India

Corresponding Author: Balachandra V Adkoli, Sri Balaji Vidyapeeth (Deemed to be University), Puducherry, India, Phone: +91 9873029295 , e-mail: balachandraa@mgmcri.ac.in

How to cite this article: Parija SC, Adkoli BV. Medical Professionalism: during COVID-19 Times and Beyond. J Basic Clin Appl Health Sci 2020;3(3):93-95.

Source of support: Nil

Conflict of interest: None

era. The edifice of professional competency is built on a sound knowledge, skills, attitudes, communication, and ethical behavior, with reflection. ${ }^{4}$ Other attributes, such as altruism, respect for others and especially the health team, duty, honesty, integrity, accountability, caring, and compassionate behavior besides passion for excellence get blended in a behavior, what we call professional behavior. 5,6

Evidence suggests that the professionalism is greatly influenced by the role models through hidden curriculum. ${ }^{7}$ The students should be exposed to rich contextual experience in diverse settings - classroom, wards, outpatient departments (OPDs), labs, campus, workplaces, and community. A four-pronged approach has been recommended, including setting clear expectations, role modeling the ideal behavior, proving rich contextual experience, and continuous feedback followed by reflection. ${ }^{8}$

A major challenge identified even before the COVID outbreak was shortage of infrastructure and faculty strength to support small groups and self-directed learning, in medical colleges with admissions more than 100 students. The second hurdle was the resistance to change. The faculty development strategy and Curriculum Implementation Support Program (CISP) launched by $\mathrm{MCl}$ is expected to help the change process. However, the COVID 
problem has paused the whole process. How are we are going to provide rich clinical and community experiences in a virtual setting? How are we going to assess and certify our graduates who have entered MBBS course in 2019? We need to find "out of the box solutions" to meet the challenges. A paradigm shift is needed in the positioning of all stakeholders - the students, teachers, medical colleges, regulators, and the civil society. It is pertinent to note that technology will occupy a central place around which the other players, members revolve (Fig.1).

\section{Role of Faculty and Students}

First of all, the students should be trained properly to engage in selfdirected learning using the new media platforms. Learning does not happen simply by watching or listening to lectures or videos. They should be familiarized with the process of learning using these resources. For this thing to happen, the faculty should be sensitized and trained to implement CBME including professionalism using virtual platform. This will require restructuring of the faculty as well as installing a well-equipped learning management system which can connect patient data (both real and simulated) with a repository of instructional materials and e-resources streaming from simulation lab which has been already recommended by the $\mathrm{MCl}$. Capturing patient record and data will have implications on ethical issues of data security and safety which needs to be addressed seriously. Will the patients give their consent for using the same for educational purpose? This requires a wide debate, and its acceptance may take time. The process of preparing e-sources can be facilitated by a consortium approach, though individual medical colleges can customize their package to their specific needs. This approach will cut down the cost, enhance quality, and speed up the process.

The implementation of virtual curriculum and assessment will obviously involve reorganization of faculty combined with retraining and skilling of the faculty in tune with the new technology and deliverables. The curriculum package may involve highquality lectures (conceptual and inspirational), demonstrations, reading assignments, mini projects, exercises, quiz, self-tests, to be complemented with collaborative learning aided by social media. This also requires a careful negotiation with student community and a close monitoring process to be in place, for preventing possible misuse.

The reorganization of the faculty cadres is inevitable. Some of the senior faculty members including curriculum committee members and medical education units may be involved in tuning the curriculum to be delivered by e-mode. Some of the faculty

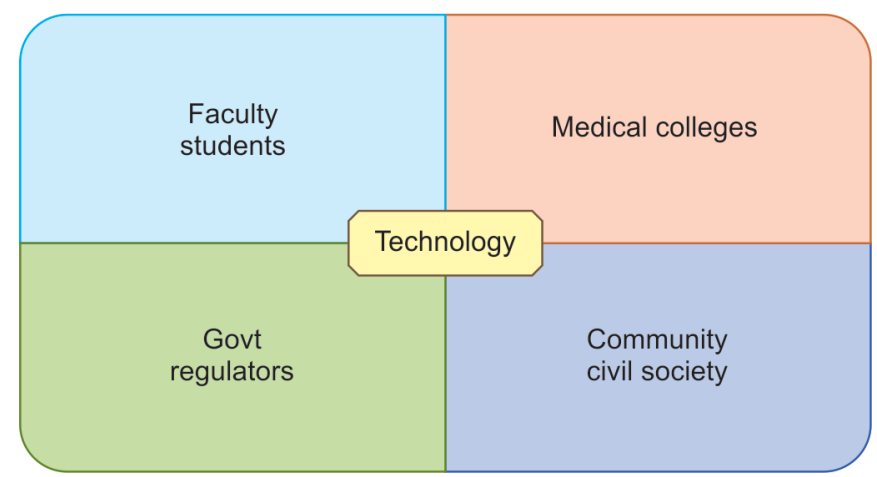

Fig. 1: The shift in the positioning of stakeholders in medical education during COVID times may be assigned for conducting e-sessions and e-workshops. The clinical faculty may be assigned the task of demonstrating high end procedural skills in association with the simulation lab. They are best suited to role model professional behavior. Role modeling of the professional behavior and the importance of hidden curriculum holds equally true for virtual learning. A large number of junior faculty and even PG residents may be deployed to play their role as mentors, and engaged in providing continuous feedback to the students by constituting small groups who will pursue collaborative learning.

We have discussed earlier, the value of rich contextual experience in infusing professionalism. The challenge of COVID time is, therefore, to capture these experiences in the online environment. For example, a short film or a documentary on how to help the needy patients, slum dwellers, migrant workers, aged couple, disabled, vulnerable population can be highly inspiring and educative. The introduction of medical humanities and theater of the oppressed (TO) have been receiving attention from medical educators. ${ }^{9}$ Students should be encouraged to post their reflections on the humanities component of the curriculum.

The assessment of professionalism in the CBME framework will be driven by extensive feedback and reflection facilitated by mentors aided by e-portfolio. ${ }^{10}$ Online tests using case scenarios and video-based triggers can be used as a part of summative exam. The assessment of the knowledge base of the professionalism, will be, in fact, more objective and efficient in the online environment.

\section{Role of Medical Colleges}

Medical colleges have a key role to play in providing necessary IT infrastructure to support e-learning resources directed to promote professionalism. A consortium approach eliciting support from technology partners would be right step to cope up with the volume and the quality of IT input needed in this mission of giant magnitude.

Setting in place a simulation lab, a communication lab, and a video studio is much needed step besides troubleshooting the connectivity issues. Orientation and training of all categories of staff as a part of the Faculty Development Program (FDP) is a must. By now, we have realized the importance of quality assurance as the central theme in medical education. A connection has to be established between the Medical Education Unit and the Internal Quality Assurance Cell (IQAC) for achieving synergy. The National Assessment and Accreditation Council (NAAC) criteria for accreditation cover all areas of functioning, but lay special emphasis on faculty development activities. ${ }^{11}$ NAAC also stresses soft skill training addressing areas like communication, leadership, team building, and conflict management all related to professionalism, to enhance patient satisfaction. The last but not least, measure to be taken by medical colleges is to introduce good governance, which supports professional behavior and punishes unacceptable behavior.

\section{Need for Interprofessional Education}

One of the key attributes of professionalism which has come to surface during COVID times is the willingness to work in teams and respect for the team members. The root cause of this problem lies in the way the health professionals are trained and deployed in service. The silos among the regulators, viz., medical council, dental council, nursing council, pharmacy council, and AYUSH stream should be broken by promoting interprofessional education. Mechanisms should be found out to see that substantial part of the community- 
based training takes place as a common curricular thread across the profession. This is not a simple task as it requires extensive planning, coordination, and overcoming ego hassles and hierarchy which is rampant across the health profession.

In conclusion, teaching of professionalism in COVID times demands a total rethinking. It requires redesigning of the curriculum, redeployment of resources, especially the IT facilities, and retraining of the faculty and students whose roles will be drastically different. The irony is that, neither we have evidence to support our strategies nor the previous experience to say that this works. What is contemplated now is a small step toward "being aware of the problem" and exploring possible solutions. Awareness leads to learning, learning leads to practice, and practice leads to perfection. That is what a medical professional aspires for, in the long run.

\section{References}

1. Parija SC, Adkoli BV. The contours of medical professionalism. J Basic Clin Appl Health Sci 2019;2(4):125-127. DOI: 10.5005/ jp-journals-10082-02231.

2. Medical Council of India. Competency based undergraduate curriculum for the Indian Medical Graduate. Medical Council of India, 2018. Available at www.mciindia.org/CMS/information-desk/ for-colleges/ug-curriculum.
3. Sahi PK, Mishra D, Singh T. Medical education amid the COVID-19 pandemic. Indian Pediatr 2020. 1-11. DOI: 10.1007/s13312-0201894-7. https://www.indianpediatrics.net/COVID29.03.2020/SA00181.pdf.

4. Epstein RM, Hundert EM. Defining and assessing professional competence. JAMA 2002;287(2):226-235. DOI: 10.1001/jama.287.2.226.

5. Passi V, Doug M, Piele E, Thistlethwaite J, Johnson N. Developing a medical professionalism in future doctors: a systematic review. Int J Med Educ 2010;1:19-29. DOI: 10.5116/ijme.4bda.ca2a.

6. Kirk LM. Professionalism in medicine: definitions and considerations for teaching. Proc (Bayl Univ Med Cent) 2007;20(1):13-16. DOI: 10.1080/08998280.2007.11928225.

7. Papadakis MA, Hodgson CS, Teherani A, etal. Unprofessional behaviour in medical schools is associated with subsequent disciplinary action by a state medical board. Acad Med 2004;79(3):244-249. DOI: 10.1097/00001888-200403000-00011.

8. Adkoli BV, Mehta M, Nayar U. Attitudes, values and professionalism. In: Bhuiyan PS, Rege N, Supe AN. The Art of Teaching Medical Students. 3rd ed., New Delhi: Elsevier; 2015. pp.203-217.

9. Ramaswamy R. "Medical humanities" for India. Indian J Med Ethics 2012;9(3):144-147. DOI: 10.20529/JME.2012.048.

10. Modi JN, Anshu, Gupta P, Singh T. Teaching and assessing professionalism in the indian context. Indian Pediatr 2014;51(11): 881-888. DOI: 10.1007/s13312-014-0521-x.

11. National Assessment and Accreditation Council (NAAC), Bengaluru, Manual of Health Sciences for Universities. Available at http://www. naac. gov.in/images/docs/Manuals/HSM-University-25Mar19.docx. 